\title{
SPATIAL DISTRIBUTION OF TEMPERATURE DURING GEOMAGNETIC DISTURBANCES
}

\author{
A.A. Karakhanyan \\ Institute of Solar-Terrestrial Physics SB RAS, \\ Irkutsk, Russia,asha@iszf.irk.ru
}

\author{
S.I. Molodykh \\ Institute of Solar-Terrestrial Physics SB RAS, \\ Irkutsk, Russia, sim@iszf.irk.ru
}

\begin{abstract}
We propose an index of efficiency of the solar activity effect on the tropospheric temperature, which takes into account the spatial irregularity of the response to this effect. As a proxy of solar activity we take the $P C$ index of geomagnetic activity, designed to monitor the geomagnetic field at high latitudes. Using NCEP/NCAR reanalysis data, we carry out a comparative analysis of variations in the proposed index and lower-troposphere temperature variations during geomagnetic disturbances. We identify the presence of a high degree of correlation between the temperature in the 925-700 $\mathrm{hPa}$ layer and the proposed index of solar activity effect. The spatio-temporal analysis of the index
\end{abstract}

and temperature variations shows that the index of efficiency of the solar activity effect describes well both the value and the sign of the observed variations in the spatial distribution of the lower-troposphere temperature as compared to the frequently used geomagnetic activity indices.

Keywords: solar activity, geomagnetic disturbance, geomagnetic activity index, temperature, humidity, solar-terrestrial relationships.

\section{INTRODUCTION}

Temperature variations near Earth's surface [Gruza et al., 2015] are now caused both by internal factors of climate variability and by processes external to the climate system. External factors that can affect climate system components can be natural, i.e. related primarily to the effect of solar and volcanic activity, or anthropogenic. Defining the role of the natural and anthropogenic factors in climate changes will promote the further development of predictive climate models.

The question of how the Sun - the primary energy source on Earth - affects processes in the lower atmosphere has been discussed for more than a century. The assertion that natural processes on Earth are controlled by solar activity was made at the beginning of the last century. With the development of ideas about solar activity effect on various meteorological and biological phenomena [Guglielmi, Ruban, 2016], the question about physical mechanisms of solar-terrestrial relationships becomes particularly interesting. It has been found that the direct effect of solar flux on surface temperature is much less than the effect of carbon dioxide [Mokhov et al., 2012]. Therefore, trigger or parametric mechanisms are being searched for in which minor effects can lead to major changes in the natural system. These mechanisms include the effect on the radiation balance in the troposphere, caused by changes in the global electric circuit due to variations in the solar wind and interplanetary magnetic field [Zherebtsov et al., 2005; Tinsley, 2000; Kniveton et al., 2008]. A number of studies analyze the impact of galactic cosmic rays on aerosol and small gas admixture in the atmosphere and hence on processes in the lower atmosphere [Pudovkin, Raspopov, 1992; Svensmark, Friis-Christensen, 1997; Mironova et al., 2015].
Nonlinear effects of solar activity on the lower atmosphere can be realized in the global circulation system. The data obtained in [Veretenenko, Ogurtsov, 2012, Karakhanyan, Molodykh, 2017] confirm that there is a considerable spatio-temporal inhomogeneity of the tropospheric response to the solar activity effect, which may be associated with circulation processes in the atmosphere. It has been found that the greatest response in the troposphere occurs at middle and high latitudes. Therefore, as a parameter that accounts for this regularity we can consider indices describing geomagnetic activity in the auroral zone - a region of maximum solar influence. It should be noted that in spatial distribution geomagnetic activity characteristics, which depend on solar activity, reflect only the latitude dependence, whereas the response of meteorological parameters to the solar activity effect has a significant longitudinal inhomogeneity. In this paper, we therefore propose an index of efficiency of the solar activity effect (ESAE), which describes this effect, taking into account tropospheric conditions before and during a geomagnetic disturbance.

\section{DATA AND ANALYSIS TECHNIQUE}

In this work, as a proxy of solar activity we take the $P C$ index of geomagnetic activity [http://www.geophys.aari.ru/pc_about.html]. This index is designed to monitor the magnetic activity in the polar cap, which is due to the geoeffective solar wind; it describes the interplanetary electric field, which affects the magnetosphere, regardless of the universal time, season, and observation point [Troshichev et al., 1988]. Moreover, unlike the planetary index aa [Zabolotnaya, 2007], which is calculated from data obtained 
at two antipodal observatories and describes global geomagnetic disturbances, the $P C$ index is calculated for each hemisphere. Variations of the $P C$ index are in good agreement with variations of the $A L$ index [Troshichev, Janzhura, 2009].

According to the model of solar activity effect on the climate system [Zherebtsov et al., 2005], the tropospheric response to heliogeophysical disturbances depends not only on the intensity of the disturbance, which can be characterized by the proxy of solar activity (geomagnetic activity index), but also on tropospheric conditions before and during a disturbance. This model assumes that solar activity variations affect magnetospheric convection through variations in solar wind and interplanetary magnetic field parameters, which, in turn, affects the distribution of electric potential difference between the ionosphere and Earth. Note that the variations in solar wind and interplanetary magnetic field parameters also have an effect on geomagnetic activity. That is why it can be used as a proxy of solar activity. Then, the changes in the ionosphere-Earth electrical potential difference lead to restructuring of the vertical profile of volume electric charge, which affects the water vapor (the main greenhouse gas) and consequently the radiation balance. Since according to the physical scheme proposed in [Zherebtsov et al., 2005] the radiation balance variations in the troposphere caused by heliogeophysical disturbances are associated with water vapor variations in the atmosphere, it can be expected that the tropospheric response to disturbances should depend on the water vapor content in this region. As a characteristic of the water vapor content in the atmosphere we use the absolute humidity.

The ESAE index, which accounts for the spatial inhomogeneity of the response to the solar influence in both latitude and longitude, is calculated by the following formula:

$$
A=k a \log |P C| \exp \left(-(\varphi-\varphi)^{2} / d \varphi^{2}\right),
$$

where $k$ is the scale factor, $a$ are anomalies of the absolute humidity, $P C$ is the geomagnetic activity index, $\varphi$ is the geographic latitude, $\varphi_{0}$ is the geographic latitude of the maximum solar activity effect $\left(\varphi_{0}=60^{\circ}\right), d \varphi$ is the coefficient characterizing the half width of the region of solar influence $\left(d \varphi=20^{\circ}\right)$. Since the $P C$ index characterizes the level of magnetic disturbance in the polar cap as a whole, an additional factor $\exp \left(-\left(\varphi-\varphi_{0}\right)^{2} / d \varphi^{2}\right)$ accounting for the latitude dependence is entered into the formula. In addition, instead of the $P C$ index, we use $\log |P C|$ because of the wide range of variations in the $P C$ index.

Using NCEP/NCAR reanalysis data [Kalnay et al,. 1996], provided by NOAA/OAR/ESRL PSD, Boulder, Colorado, USA [https: //www.esrl.noaa.gov/psd], and the proposed formula, we have constructed maps of the ESAE index during heliogeophysical disturbances (with regard to water vapor). Daily average distributions of anomalies of the absolute humidity in the $925-700 \mathrm{hPa}$ layer were calculated as deviations from the mean for fifteen days before a disturbance.

To conduct the comparative analysis, we used the NCEP/NCAR reanalysis data to construct maps of daily average temperature anomalies in the $925-700 \mathrm{hPa}$ layer, calculated as deviations from the mean for fifteen days (approximately two synoptic periods of baric structures) before the disturbance onset. The synoptic period of cyclones and anticyclones is from three to ten days. The average of the two synoptic periods is chosen as a norm for calculating anomalies to minimize the impact on the results of the analysis both of synoptic processes and of seasonal variation.

Coefficients of linear correlation between variations of temperature anomalies and ESAE index for different regions during disturbances.

\begin{tabular}{|c|c|c|c|c|}
\hline Date flares & $\begin{array}{c}* \text { Coordinates of centers for } \\
\text { regions with higher } \\
\text { temperature } \\
\text { on 0 day of disturbance }\end{array}$ & $\begin{array}{c}\text { Correlation coefficient } \\
\text { for regions } \\
\text { with higher } \\
\text { temperature, } R_{\mathrm{T} \_\mathrm{A}}\end{array}$ & $\begin{array}{c}\text { *Coordinates of centers } \\
\text { for regions with lower } \\
\text { temperature } \\
\text { on 0 day of disturbance }\end{array}$ & $\begin{array}{c}\text { Correlation coefficient } \\
\text { for regions } \\
\text { with lower } \\
\text { temperature, } R_{\mathrm{T} \_\mathrm{A}}\end{array}$ \\
\hline March 22, 2002 & $60^{\circ} \mathrm{N}, 130^{\circ} \mathrm{W}$ & $0.90 \pm 0.18$ & $80^{\circ} \mathrm{N}, 135^{\circ} \mathrm{W}$ & $0.93 \pm 0.15$ \\
\hline & $65^{\circ} \mathrm{N}, 40 \mathrm{~W}$ & $0.94 \pm 0.14$ & $50^{\circ} \mathrm{N}, 15^{\circ} \mathrm{E}$ & $0.90 \pm 0.18$ \\
\hline April 16, 2002 & $50^{\circ} \mathrm{N}, 160^{\circ} \mathrm{W}$ & $0.68 \pm 0.26$ & $65^{\circ} \mathrm{N}, 165^{\circ} \mathrm{E}$ & $0.96 \pm 0.10$ \\
\hline June 16,2005 & $65^{\circ} \mathrm{N}, 100^{\circ} \mathrm{W}$ & $0.91 \pm 0.17$ & $55^{\circ} \mathrm{N}, 120^{\circ} \mathrm{W}$ & $0.64 \pm 0.31$ \\
\hline & $50^{\circ} \mathrm{N}, 15^{\circ} \mathrm{E}$ & $0.88 \pm 0.18$ & $65^{\circ} \mathrm{N}, 60^{\circ} \mathrm{E}$ & $0.85 \pm 0.20$ \\
\hline September 07, 2005 & $70^{\circ} \mathrm{N}, 180^{\circ} \mathrm{E}$ & $0.90 \pm 0.18$ & $75^{\circ} \mathrm{N}, 90^{\circ} \mathrm{W}$ & $0.97 \pm 0.10$ \\
\hline & $80^{\circ} \mathrm{N}, 105^{\circ} \mathrm{E}$ & $0.51 \pm 0.35$ & $65^{\circ} \mathrm{N}, 140^{\circ} \mathrm{E}$ & $0.56 \pm 0.34$ \\
\hline & $55^{\circ} \mathrm{N}, 50^{\circ} \mathrm{W}$ & $0.78 \pm 0.26$ & $70^{\circ} \mathrm{N}, 45^{\circ} \mathrm{E}$ & $0.93 \pm 0.15$ \\
\hline
\end{tabular}

*Table lists coordinates of centers for regions under study, the size of which is $5^{\circ} \times 5^{\circ}$.

Note that the presence of long-term variations of solar activity (with periods over 30 years) precludes using the commonly used norm from 1961 and 1990 to account for seasonal variations.

\section{RESULTS AND DISCUSSION}

To compare the spatial distribution of the proposed ESAE index with the distribution of temperature anomalies, we have constructed a sequence of maps of these parameters for some heliogeophysical disturbances with the daily average $P C$ index $>1.5$ (see Table). As an example, Figure 1 shows a variation in the spatial distribution of temperature anomalies and ESAE index during the geomagnetic disturbance caused by the solar flare of September 07, 2005. Results of the comparative analysis demonstrate the similarity between variations in the spatial distribution of temperature and ESAE index. We can clearly see several distinct regions of positive 


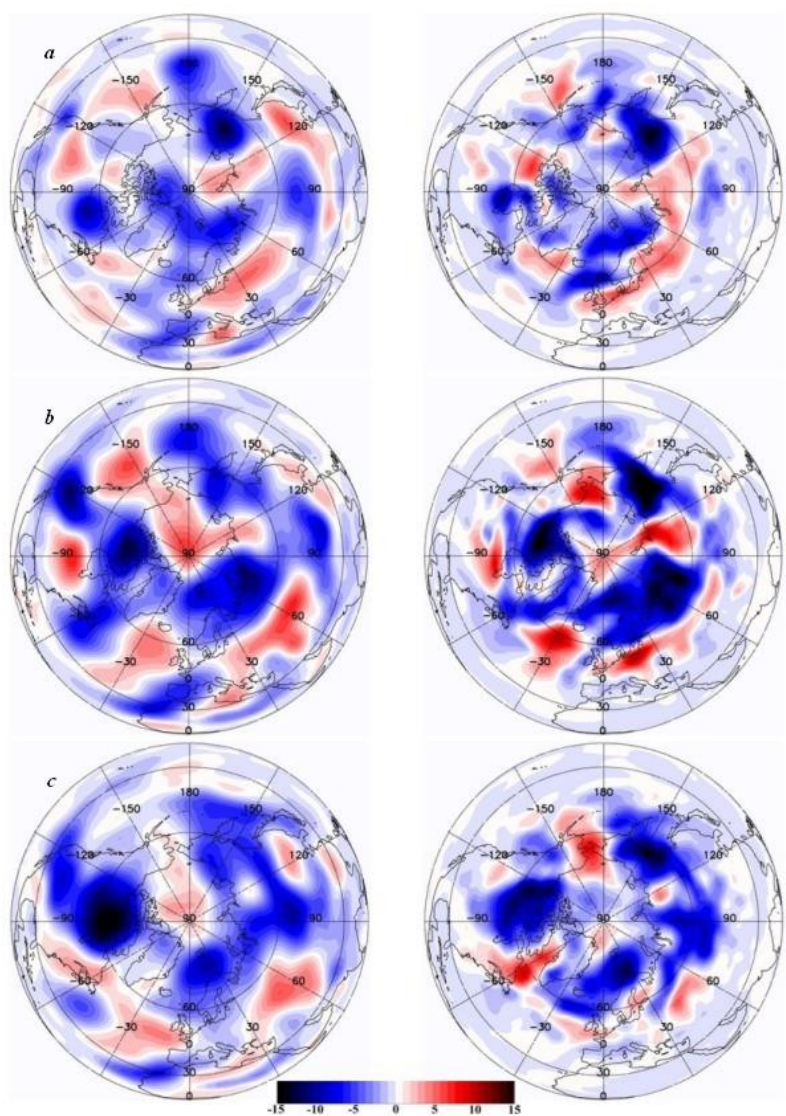

Figure 1. Spatial distribution of temperature anomalies (left) and ESAE index (right) during a geomagnetic disturbance: $a$ - the disturbance onset (September 08, 2005); $b-$ its maximum (September 11, 2005); $c$ - its end (September 14, 2005)

and negative changes in the characteristics considered. The spatial distribution of the correlation coefficient between temperature anomalies and ESAE index is displayed in Figure 2. The similarity in the variation of the spatial distribution of temperature and the proposed index suggests that this index does reflect the spatial structure of the temperature response to geomagnetic disturbance.

It is interesting to examine the temporal dynamics of temperature anomalies and ESAE index for different regions during a disturbance. For the analysis, we have selected regions with the largest amplitude of variations of the parameters under study. The analysis has shown that during disturbances in different regions temporal variations of temperature anomalies are similar to ESAE-index variations (see Table). Figure 3 presents the averaged temporal dynamics of temperature anomalies, ESAE-index variations, $P C$ - and $a a$-index variations for regions with higher temperature. The data in Figure 3 indicate that an increase in the ESAE index is accompanied by a temperature increase in these regions. Note that for these regions the fact that water vapor is taken into account in the ESAE index leads to an increase in the linear correlation coefficient ( $R=0.94 \pm 0.14)$ while the correlation coefficient between temperature variations and variations in the geomagnetic activity indices is $0.80 \pm 0.24$. Figure 4 displays the

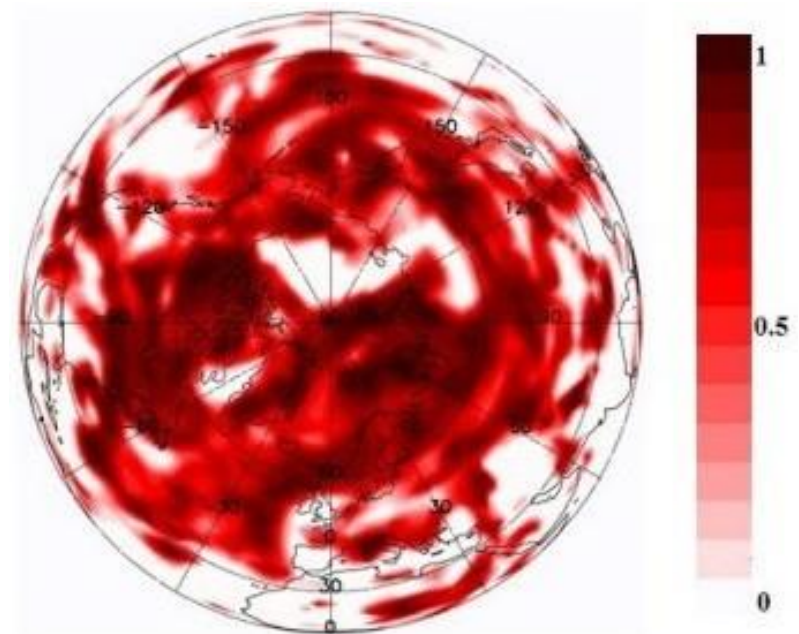

Figure 2. Spatial distribution of the correlation coefficient between temperature anomalies and ESAE index during the geomagnetic disturbance associated with the solar flare of September 07, 2005

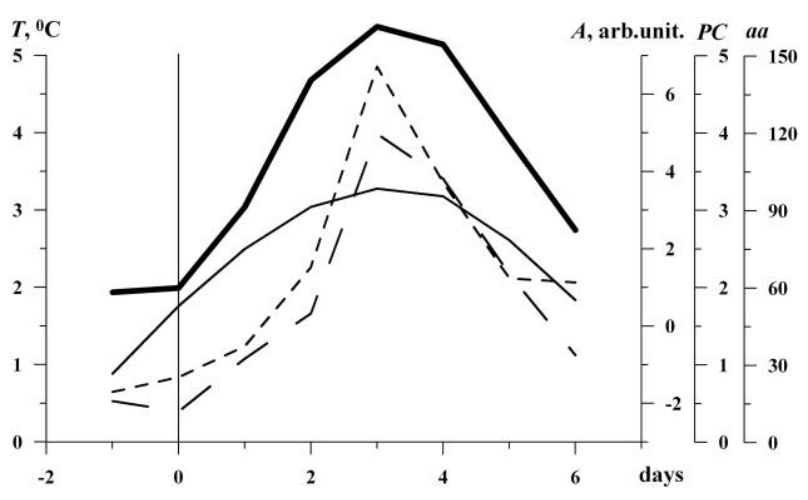

Figure 3. Temporal dynamics of temperature anomalies (thin line), ESAE index (thick line), variations of $P C$ index (short dashes) and $a a$ index (long dashes) for regions with higher temperatures during the geomagnetic disturbance. 0 is the day of the geomagnetic disturbance onset (September 08, 2005)

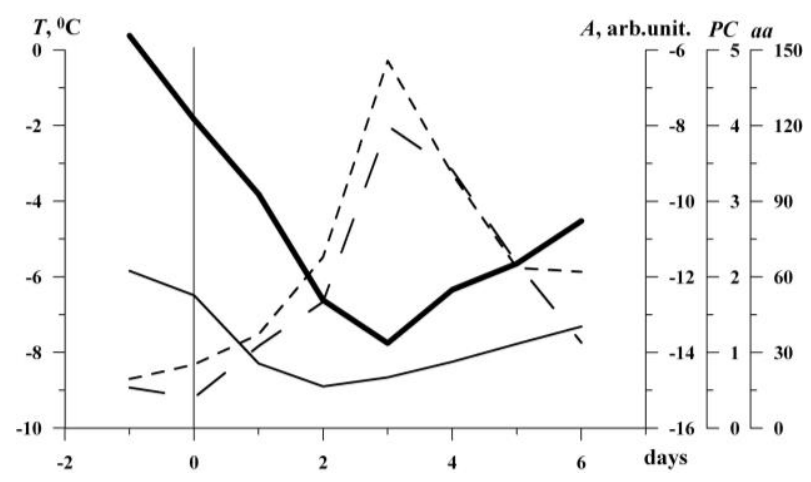

Figure 4. Temporal dynamics of temperature anomalies (thin line), ESAE index (thick line), variations of $P C$ index (short dashes) and $a a$ index (long dashes) for regions with lower temperature during the geomagnetic disturbance. 0 is the day of the geomagnetic disturbance onset (September 08, 2005)

temporal dynamics of temperature anomalies, ESAEindex variations, $P C$ - and $a a$-index variations, averaged for regions with lower temperature. The comparative analysis of the data presented in Figure 4 shows that 
a decrease in the ESAE index is accompanied by a temperature decrease. For regions with lower temperature, accounting for water vapor leads to the fact that variations in temperature and ESAE index $(R=0.92 \pm 0.16)$ correlate. Notice that in regions with lower temperature, temperature variations anticorrelate with $P C$ - and $a a$-index variations $(R=-0.68 \pm 0.30)$.

\section{CONCLUSIONS}

Our findings suggest the following conclusions.

1. The index of efficiency of the solar activity effect has been proposed which describes the solar activity effect on the troposphere with regard to the spatial inhomogeneity of tropospheric response to the solar influence both in latitudinal and longitudinal direction.

2. The results of the analysis of spatio-temporal structure of temperature and ESAE-index variations suggest a high degree of correlation between temperature and the proposed index.

3. The ESAE index describes well the observed variations in the spatial distribution of temperature in the lower troposphere both in magnitude and in sign, as compared to the commonly used indices of geomagnetic activity.

We thank referees for useful comments.

The work was performed with budgetary funding of Basic Research program II.16, and with the support of Program No. 51 "Climate change: causes, risks, consequences, problems of adaptation and regulation" by the Presidium of the Russian Academy of Sciences.

\section{REFERENCES}

Gruza G.V., Rankova E.Ya., Rocheva E.V., Smirnov V.D. Geographic and seasonal features of the present global warming. Fundamentalnaya i prikladnaya klimatologiya [Fundamental and Applied Climatology]. 2015, vol. 2, pp. 41-62. (In Russian).

Guglielmi A.V., Ruban V.F. To the 120th anniversary of A.L. Chizhevsky's birth. Solar-Terr. Phys. 2016, vol. 2, no. 4, pp. 126-133. DOI: 10.12737/24279.

Kalnay E., Kanamitsu M., Kistler R., Collins W., Deaven D., et al. The NCEP/NCAR 40-Year Reanalysis Project. Bull. Amer. Meteor. Soc. 1996, vol. 77, no. 3, pp. 437-470. DOI: 10.1175/ 1520-0477(1996)077<0437:TNYRP>2.0.CO;2.

Karakhanyan A.A., Molodykh S.I. Evolution of extratropical cyclones during disturbed geomagnetic conditions. Geomagnetism and Aeronomy. 2017, vol. 57, no. 5, pp. 535-540. DOI: $10.1134 /$ S0016793217050115.

Kniveton D.R., Tinsley B.A., Burns G.B., Bering E.A., Troshichev O.A. Variations in global cloud cover and the fairweather vertical electric field. J. Atmos. Solar-Terr. Phys. 2008 , vol. 70, no. 13, pp. 1633-1642. DOI: 10.1016/j.jastp.2008.07.001.

Mironova I.A., Aplin K.L., Arnold F., Bazilevskaya G.A., Harrison R. G., Krivolutsky A.A., Nicoll K.A., Rozanov E.V., Turunen E., Usoskin I.G. Energetic particle influence on the Earth's atmosphere. Space Sci. Rev. 2015, vol. 194, no. 1-4, pp. 1-96. DOI: 10.1007/s11214-015-0185-4.

Mokhov I.I., Smirnov D.A., Karpenko A.A. Assessments of the relationship of changes of the global surface air temperature with different natural and anthropogenic factors based on observations // Doklady Earth Sciences. 2012, vol. 443, no. 1, pp. 381-387. DOI: 10.1134/S1028334X12030178.

Pudovkin M.I., Raspopov O.M. Mechanism of the solar activity effect on the low atmosphere state and meteoparameters (Overview). Geomagnetizm i aeronomiya [Geomagnetism and Aeronomy]. 1992, vol. 32, no. 5, pp. 1-22. (In Russian).

Svensmark H., Friis-Christensen E. Variation of cosmic ray flux and global cloud coverage - a missing link in solar-climate relationships. J. Atmos. Solar-Terr. Phys. 1997, vol. 59, no. pp. 1225-1232. DOI: 10.1016/S1364-6826(97)00001-1.

Tinsley B.A. Influence of solar wind on the global electric circuit, and inferred effects on cloud microphysics, temperature, and dynamics in the troposphere. Space Sci. Rev. 2000, vol. 94, no. 1-2, pp. 231-258.

Troshichev O.A., Andrezen V.G., Vennerstrom S., FriisChristensen E. Magnetic activity in the polar cap - A new index. Planet. Space Sci. 1988, vol. 36, no. 11, pp. 1095-1102. DOI: 10.1016/0032-0633(88)90063-3.

Troshichev O.A., Janzhura A. Relationship between the PC and $\mathrm{AL}$ indices during repetitive bay-like magnetic disturbances in the auroral zone. J. Atmos. Solar-Terr. Phys. 2009, vol. 71, no. 12, pp. 1340-1352. DOI: 10.1016/j.jastp.2009.05.017.

Veretenenko S.V., Ogurtsov M.G. Study of spatial and temporal structure of long-term effects of solar activity and cosmic ray variations on the lower atmosphere circulation. Geomagnetism and Aeronomy. 2012, vol. 52, no. 5, pp. 591602. DOI: $10.1134 / \mathrm{S} 0016793212050143$.

Zabolotnaya N.A. Indeksy geomagnitnoi aktivnosti. Spravochnoe posobie [Geomagnetic Activity Indices]. Handbook. 2-nd Edition. Moscow, LKI Publ., 2007, 88 p. (In Russian).

Zherebtsov G.A., Kovalenko V.A., Molodykh S.I., Rubtsova O.A. The model of solar activity effect on climatic characteristics of the Earth's troposphere. Optika atmosfery I okeana [Atmospheric and Oceanic Optics]. 2005, vol. 18, no. 12, pp. 1042-1050. (In Russian).

URL: http://www.geophys.aari.ru/pc_about.html (accessed May 11, 2018). 2018).

URL: https://www.esrl.noaa.gov/psd (accessed May 11,

How to cite this article

Karakhanyan A.A., Molodykh S.I. Spatial distribution of temperature during geomagnetic disturbances. Solar-Terrestrial Physics. 2018. Vol. 4. Iss. 4. P. 59-62. DOI: $10.12737 /$ stp-43201808. 